\title{
Physiological response of hemostasis of piglets to excessive thermal effects
}

\author{
Marina V. Mekhanikova*, Svetlana V. Shestakova, and Tatyana P. Ryzhakina \\ Vologda State Dairy Farming Academy named after N.V. Vereshchagin, Vologda 160555, Russia
}

\begin{abstract}
Currently, the pig feels the need to further clarify aspects of the physiology of pigs. It is very important to clarify the changes of functional parameters of piglets at the impact of any environmental factors. Negative environmental impact can often particularly adversely affect hemostasis. However, changes its parameters clarified weakly. Objective: to assess changes in hemostasis in piglets undergoing overheating. The research involved 42 pigs at the age of 2.5 months breed: large white, which has experienced overheating during 3 hours as a result of breakdown of air conditioning system. The control group included 32 healthy animals kept in normal conditions of a pigsty. The experienced piglets determined significant increase of platelet aggregation that occur spontaneously and in response to stimulation. Experienced pigs blood coagulation was found high and significant weakening of fibrinolysis. Apparently, the overheating affects animals' haemorheology and significantly inhibits anabolism. It is clear that in piglets, which suffered from overheating, activated hemostatic system, which affects the microcirculation and inhibits growth. For this reason, there is a great need in the search approaches for leveling in piglets undergoing an episode of overheating, excessive activity of blood coagulation and increased platelet aggregation.
\end{abstract}

\section{Introduction}

Modern pig production is now one of the very profitable sectors of agriculture providing the population of many countries of the world high quality meat and fat $[1,2]$. Now the pig is still in dire need in addition to physiological knowledge of pigs of different age [3]. Therefore great importance is a detailed study of the mechanisms of functioning of regulatory systems in growing pigs that fall in different environmental conditions [4], is able to affect them adversely [5, 6]. The study of possible changes in the body of pigs at any stage of ontogeny to outside influence is required to improve the methods used to preserve their health, increase their productivity and optimum reproduction [7]. For reasonable use of new physiological knowledge about pigs to practice on will help to create a good scientific basis to maintain their optimal functional status any changes of the environment [8]. This will provide a high level of productivity at minimal cost [9].

Serious issue of practice of pig production is its intensification due to acceleration of the process of growing livestock in the achievement of safety stock, even in adverse environmental conditions due to the use of physiologically sound options for feeding and housing [10]. The understanding, which is very important for optimum productivity of piglets at any age, is indicators of his blood [11-13]. It is clear that blood is a labile marker of the functional characteristics of the organism responsive to external stimuli $[14,15]$. The changes in the activity of all organs and systems of the body in the process of metabolism always affect the blood parameters. The blood also changes its composition and parameters of hemostasis and controls the functional manifestations of the organism [16, 17].

To save the piglets' optimum homeostasis enormous importance of optimum circulation through the vessels is closely associated with the level of activity of hemostasis. The overall viability of the body and its functional activity are strongly determined by hemorheology $[18,19]$. This is of great importance the activity of hemostasis [20]. For this reason, the activity of hemostasis strongly identifies anabolism in the body and its productive capacities [21]. Because of the large physiological significance and vulnerability of homeostasis now he started to study animals in different environmental conditions.

It was previously clarified that in case of negative impacts on the body quickly develop negative changes in the work of hemostasis, which weakens hemocirculation in organs [22]. Their characteristic in pigs of any age in conditions of optimum environment is poorly explored. The dynamics of hemostasis has negative environmental effects on their body. The piglets are vulnerable in terms of metabolism, growth rate and overall viability. This may have the effect of many physical and chemical effects. Very frequent ones are variations of temperature environment, which dictates the need to find out their influence on the activity of the hemostatic system.

* Corresponding author: ilmedv1@yandex.ru 
Objective: to evaluate changes in the hemostatic system in piglets after overheating.

\section{Materials and methods}

The work was carried out in accordance with the ethics established by the European Convention for the protection of vertebrate animals used for experimental and other scientific purposes (adopted in Strasbourg on 18 March 1986 and confirmed in Strasbourg on 15 June 2006).

The study was carried out in 42 healthy piglets contained in the farms of the Samara region of Russia, referring to the large white breed. All piglets were aged 2.5 months. The studied pigs were exposed to an accidental overheating, due to the temporary outages during the summer air-conditioning in the barn. As a result, the piglets suffered overheating in the form of a stay for 3 hours in the environment of high temperature of $10^{\circ} \mathrm{C}$. These pigs made up the experimental group. The control group consisted of 32 pigs never exposed to the negative environmental effects that were completely healthy. Dietary intake of all pigs was standard.

All piglets were found in the blood fibrinogen concentration, using a modified Claus technique. The level of plasminogen was determined they have kinetic method with the help of the device FP-901 ("LabSystems", Finland) and chromogenic substrate ("Dade Behring", Germany). The concentration of soluble fibrin-monomer complexes was assessed using a visual method using reagents manufactured by Tekhnologiya-Standart (Russia). Activated partial thromboplastin time was recorded with the coagulometer "HumaClot" ("HUMAN GmbH", Germany) and a set of reagents produced HemoStat aPTT-EL. The value of the international normalized ratio was determined using the method of Quick. Platelet aggregation was determined turbidimetrically method using dual-channel laser aggregometer ("Biola", Russia) using a $0.5 \mu \mathrm{m}$ solution of adenosine diphosphate (ADP). Statistical data processing was carried out by t-criterion of student.

\section{Results}

In the course of assessing the activity of hemostasis in piglets that fell under conditions of overheating, it was possible to establish the activation of platelets and the coagulation system with a decrease in the possibility of fibrinolysis (table).

In animals that made up the experimental group, a $21.2 \%$ decrease in the duration of activated partial thromboplastin time, a decrease of $7.9 \%$ in the international normalized ratio and a decrease in plasma plasminogen level $(8.9 \%)$, a $32.0 \%$ increase in fibrinogen concentration and an increase of $23.1 \%$ in the amount of soluble fibrin-monomer complexes. At the same time, in piglets after overheating, spontaneous (by $21.8 \%$ ) and stimulated (by $21.0 \%$ ) platelet aggregation were enhanced.
Table 1. Hemostasis disorders in examined piglets

\begin{tabular}{|l|c|c|}
\hline \multicolumn{1}{|c|}{$\begin{array}{c}\text { Registrated } \\
\text { parameters }\end{array}$} & $\begin{array}{c}\text { Experienced } \\
\text { group, } \mathrm{n}=42\end{array}$ & $\begin{array}{c}\text { Control } \\
\text { group, } \mathrm{n}=32\end{array}$ \\
\hline $\begin{array}{l}\text { The magnitude of the } \\
\text { international normalized } \\
\text { relationship }\end{array}$ & $1.13 \pm 0.13^{*}$ & $1.22 \pm 0.09$ \\
\hline $\begin{array}{l}\text { Partial activated } \\
\text { thromboplastin time, sec }\end{array}$ & $30.6 \pm 0.82^{* *}$ & $37.1 \pm 0.69$ \\
\hline $\begin{array}{l}\text { The concentration of } \\
\text { fibrinogen, g/l }\end{array}$ & $3.3 \pm 0.31^{* *}$ & $2.5 \pm 0.23$ \\
\hline $\begin{array}{l}\text { The concentration of soluble } \\
\text { fibrin-monomer complexes, } \\
\text { mg/dl }\end{array}$ & $3.2 \pm 0.24^{*}$ & $2.6 \pm 0.82$ \\
\hline $\begin{array}{l}\text { Plasminogen activity level, } \\
\%\end{array}$ & $86.3 \pm 0.32^{*}$ & $94.0 \pm 0.57$ \\
\hline $\begin{array}{l}\text { Activity of spontaneous } \\
\text { platelet aggregation, units }\end{array}$ & $1.23 \pm 0.10^{* *}$ & $1.01 \pm 0.10$ \\
\hline $\begin{array}{l}\text { Stimulated Platelet } \\
\text { Aggregation Activity } 0.5 \mu \mathrm{m} \\
\text { ADP, units }\end{array}$ & $2.42 \pm 0.16^{* *}$ & $2.00 \pm 0.21$ \\
\hline Not statical significan & & \\
\hline
\end{tabular}

Note: the statistical significance of the differences in the indicators in the experimental group and the control group * $\mathrm{p}<0.05, * *-\mathrm{p}<0.01$.

\section{Discussion}

Modern pig breeding strongly needs to continue the accumulation of knowledge on the physiology of pigs $[23,24]$. The study of aspects of their blood under the influence of negative environmental factors is highly relevant [25]. This information is of great importance for the practice of pig farming. The application of this knowledge will help to improve approaches to the health of piglets to increase their growth and achieve maximum preservation of the livestock [26].

Long-term studies on the physiology of pigs have not yet helped to accumulate the necessary amount of knowledge on the main points of the physiology of blood in young animals. In this regard, there is a great need for a further assessment of blood work in relation to the work of the whole organism of piglets caught in any adverse environmental conditions [27].

Genetically determined ontogenesis changes the intensity of its course in the case of the influence of different environmental factors. In piglets, this is manifested under the influence of negative influences with changes in blood counts and hemocirculation [28]. A major role in this is played by disturbances in the processes in the capillaries. This disrupts many physiological processes in the body that control blood parameters. Her condition is considered an important factor in maintaining homeostasis in all animals [29].

Apparently, the course of ontogenesis is accompanied by some activation of adaptation to environmental changes due to the activation of many mechanisms, among which hemostasis occupies a central place. This stimulates vital activity and maintains optimum piglet health [30].

Being clearly genetically programmed, hematological parameters can change their manifestation against the background of influences on the body from the outside. For this reason, it is very important to continue the in- 
depth study of many aspects of the body under many negative environmental influences and evaluate their consequences. The continuation of research on the physiology of piglets is called upon to form a reliable basis for optimizing options for their maintenance and feeding. By summarizing the new information and its application in practice, undoubtedly, a serious intensification of all pig production will be achieved [31].

It was previously found that the hemostatic system is able to quickly respond to changes in the environment by the onset of dysfunctions [32]. It is recognized that increased peroxidation processes rapidly weaken the reactivity of the animal. At the same time, the activity of hemostasis rapidly increases, which violates the rheological parameters of the blood. Their appearance leads to microcirculation dysfunctions and a weakening of metabolism [33].

Recognizing the great importance of understanding the dynamics of the mechanisms of hemostasis, in piglets affected by adverse influences, it was decided to conduct this study. It is clear that with much environmental degradation in animals very often changes in hematological parameters occur.

In this work, it was found that with overheating in piglets, hemostasis functions are enhanced. This suggests that this is caused by the activation of hemocoagulation processes with the inclusion of two mechanisms. Apparently, this is due to an increase in the activity level of the main number of coagulation factors. This leads in piglets to strong thromboplastin generation and increased activation of factor XII. It is also associated with an increase in the concentration of fibrinogen and fibrinogen fragments in their blood. This indicates an increase in the activity of its polymerization, which weakly restrains weakened fibrinolysis [34].

It becomes clear that the weakening of the antioxidant properties of the body enhances platelet aggregation spontaneous and stimulated. An important mechanism of this in piglets is depression of the synthesis of cyclic adenosine monophosphate in platelets and an increase in the formation of thromboxane A2 molecules [30].

Researchers are forming an opinion about a clear connection between the somatic parameters of the body and the features of its hematological characteristics. In the study, a small stage of the early ontogenesis of animals was traced, which does not give grounds to draw serious conclusions about short-term overheating of hemostasis activity in the future [35].

However, the found changes in the work of hemostasis of piglets in the case of adverse influences from the outside are a strong incentive to continue research on changes in hemostasis activity during the growth of piglets [36].

\section{Conclusion}

Modern pig farming is in dire need of new information on physiology of pigs. It is necessary to study the work of the internal organs of pigs are influenced by negative environmental factors. Of great importance in maintaining optimum homeostasis and their high productivity of pigs have them for many hematological parameters. During early ontogenesis in pigs there is a fluctuation in physiological parameters. Of particular significance is the dynamics of blood parameters including hemostasis. Great biological importance is the level of platelet aggregation and coagulation activity. The work found that overheating in piglets leads to increased activity of hemostasis. These piglets increased activity of the coagulation, fibrinolysis weakening and enhanced platelet aggregation. This negatively affects animals' hemocirculation, impairing the metabolism in tissues, and inhibits gains.

\section{References}

1. V.I. Maksimov, S.Yu. Zavalishina, A.V. Parakhnevich, E.N. Klimova, N.A. Garbart, A.A. Zabolotnaya, Yu.I. Kovalev, T.Yu. Nikiforova, E.I. Sizoreva, Physiological Dynamics of Microrheological Characteristics Of Erythrocytes In Piglets During The Phase Of Milk Nutrition, Res. J. of Pharmaceut., Biolog. and Chemical Sci., 9(5), 454-459 (2018)

2. E.S. Tkacheva, S.Yu. Zavalishina, Physiological Features Of Platelet Aggregation In Newborn Piglets, Res. J. of Pharmaceut., Biolog. and Chemical Sci., 9(5), 36-42 (2018)

3. T.I. Glagoleva, S.Yu. Zavalishina, G.S. Mal, O.N. Makurina, I.A. Skorjatina, Physiological Features Of Hemo-coagulation In Sows During Sucking, Res. J. of Pharmaceut., Biolog. and Chemical Sci., 9(4), 29-33 (2018)

4. E.S. Tkacheva, S.Yu. Zavalishina, Physiology of Platelet Hemostasis In Piglets During The Phase Of Newborns, Res. J. of Pharmaceut., Biolog. and Chemical Sci., 9(5), 1912-1918 (2018)

5. V.I. Maksimov, S.Yu. Zavalishina, A.V. Parakhnevich, E.N. Klimova, N.A. Garbart, A.A. Zabolotnaya, Yu.I. Kovalev, T.Yu. Nikiforova, E.I. Sizoreva, Functional Activity of The Blood Coagulation System Against The Background Of The Influence Of Krezacin And Gamavit In Newborn Piglets Who Underwent Acute Hypoxia, Res. J. of Pharmaceut., Biolog. and Chemical Sci., 9(5), 20372042 (2018)

6. I.N. Medvedev, The Physiological Properties Of Platelets In People 18-35 Years Old, Trained In The Section Of General Physical Training, Res. J. of Pharmaceut., Biolog. and Chemical Sci., 9(6), 1277-1283 (2018)

7. I.N. Medvedev, Functional Parameters Of Platelets In Young Men Practicing In The Football Section, Res. J. of Pharmaceut., Biolog. and Chemical Sci., 9(6), 1315-1320 (2018)

8. E.S. Tkacheva, S.Yu. Zavalishina, Physiological Aspects Of Platelet Aggregation In Piglets Of Milk 
Nutrition, Res. J. of Pharmaceut., Biolog. and Chemical Sci., 9(5), 74-80 (2018)

9. I.N. Medvedev, Functional Properties Of Platelets In Amateur Tennis Players Aged 18-35 Years, Res. J. of Pharmaceut., Biolog. and Chemical Sci., 9(6), 1370-1375 (2018)

10. S.Yu. Zavalishina, Physiological Mechanisms of Hemostasis In Living Organisms, Res. J. of Pharmaceut., Biolog. and Chemical Sci., 9(5), 629-634 (2018)

11. Ju.L. Oshurkova, I.N. Medvedev, Functional Features Of Platelets In Newborn Calves Ayrshire Breed, Res. J. of Pharmaceut., Biolog. and Chemical Sci., 9(6), 313-318 (2018)

12. S.Yu. Zavalishina, Functional Activity Of Plasma Hemostasis In Neonatal Calves With Iron Deficiency, Who Received Ferroglucin And Glycopin, Res. J. of Pharmaceut., Biolog. and Chemical Sci., 9(5), 1186-1191 (2018)

13. I.N. Medvedev, Functional Features Of Platelets In Candidates And Masters Of Sports In The Athletics Of Adolescence, Res. J. of Pharmaceut., Biolog. and Chemical Sci., 9(6), 1395-1400 (2018)

14. I.V. Amelina, I.N. Medvedev, Relationship between the chromosome nucleoli-forming regions and somatometric parameters in humans, Bull. of Experim. Biology and Med., 147(1), 77-80 (2009)

15. I.N. Medvedev, Physiological Characteristics of Platelet Activity In Young People Experiencing Moderate Exercise, Res. J. of Pharmaceut., Biolog. and Chemical Sci., 9(6), 1416-1421 (2018)

16. I.N. Medvedev, The Physiological State Of Intravascular Platelet Activity In Young Men Who Had High Normal Blood Pressure, Overweight Or A Combination Of Them And Started Regular Exercise, Res. J. of Pharmaceut., Biolog. and Chemical Sci., 9(6), 1438-1445 (2018)

17. G.S. Mal, N.V. Vorobyeva, A.V. Makhova, I.N. Medvedev, I.I. Fayzullina, Features Of Physical Rehabilitation After Myocardial Infarction, Res. J. of Pharmaceut., Biolog. and Chemical Sci., 9(6), 280-285 (2018)

18. G.S. Mal, E.L. Kharitonov, N.V. Vorobyeva, A.V. Makhova, I.N. Medvedev, Functional Aspects of Body Resistance, Res. J. of Pharmaceut., Biolog. and Chemical Sci., 9(6), 60-65 (2018)

19. I.N. Medvedev, Functional Features Of Intravascular Platelet Activity In Adolescents With High Normal Blood Pressure, Overweight Or A Combination Of Them Against The Background Of Regular Physical Exertion, Res. J. of Pharmaceut., Biolog. and Chemical Sci., 9(6), 1258-1265 (2018)

20. T.I. Glagoleva, I.N. Medvedev, Physiological Features Of Anti-aggregational Control Of Blood Vessels Over The Shaped Elements Of Blood In Calves At The Onset Of Ontogenesis, Res. J. of Pharmaceut., Biolog. and Chemical Sci., 9(5), 440-447 (2018)
21. S.Yu. Zavalishina, Functional Properties Of Coagulation Hemostasis In Calves During The Phase Of Dairy-Vegetative Nutrition, Res. J. of Pharmaceut., Biolog. and Chemical Sci., 9(5), 784-790 (2018)

22. I.N. Medvedev, Physiological Response Of Intravascular Platelet Activity In Boys With High Normal Blood Pressure To Regular Physical Exercise, Res. J. of Pharmaceut., Biolog. and Chemical Sci., 9(6), 1244-1250 (2018)

23. I.N. Medvedev, O.V. Gamolina, Lisinopril effects on platelet activity in patients with arterial hypertension and impaired glucose tolerance, Russ. J. of Cardiol., 3, 45-48 (2008)

24. S.Yu. Zavalishina, Physiological Features Of Vascular Hemostasis In Calves Of Dairy-Vegetative Food, Res. J. of Pharmaceut., Biolog. and Chemical Sci., 9(5), 1137-1143 (2018)

25. S.Yu. Zavalishina, Functional Antiaggregatory Properties Of Blood Vessels In Calves During Transition From Dairy To Plant Type Of Nutrition, Res. J. of Pharmaceut., Biolog. and Chemical Sci., 9(5), 1110-1116 (2018)

26. S.Yu. Zavalishina, Functioning Of Mechanisms Of Hemocoagulation Restriction In Calves At Change Of Methods Of Nutrition, Res. J. of Pharmaceut., Biolog. and Chemical Sci., 9(5), 800-806 (2018)

27. S.Yu. Zavalishina, Functioning Of Platelets In Milk And Vegetable Nutrition Calves, Res. J. of Pharmaceut., Biolog. and Chemical Sci., 9(5), 943-949 (2018)

28. I.N. Medvedev, T.A. Kumova, Angiotensin II receptor inhibitors: role and place in arterial hypertension and metabolic syndrome treatment, Russ. J. of Cardiol., 5, 97-99 (2007)

29. Ju.L. Oshurkova, I.N. Medvedev, Physiological Indicators Of Platelets In Ayrshire Calves During The Dairy Feeding Phase, Res. J. of Pharmaceut., Biolog. and Chemical Sci., 9(6), 171-176 (2018)

30. I.N. Medvedev, T.A. Kumova, Valsartan effects on platelet activity in patients with arterial hypertension and metabolic syndrome, Russ. J. of Cardiol., 3, 66-69 (2007)

31. S.Yu. Zavalishina, Functional Features Of Platelets In Newborn Calves With Iron Deficiency, Res. J. of Pharmaceut., Biolog. and Chemical Sci., 9(5), 1153-1158 (2018)

32. N.V. Vorobyeva, I.N. Medvedev, Functional activity of platelets in new-born calves of black-marked breed, Bulgar. J. of Agricultur. Sci., 25(3), 570-574 (2019)

33. S.Yu. Zavalishina, Functional Properties Of Anticoagulation And Fibrinolysis In Calves Of Plant Nutrition, Res. J. of Pharmaceut., Biolog. and Chemical Sci., 9(5), 1082-1087 (2018)

34. S.Yu. Zavalishina, Physiology of Vascular Hemostasis In Newborn Calves, Res. J. of 
Pharmaceut., Biolog. and Chemical Sci., 9(5), 1037-1044 (2018)

35. S.Yu. Zavalishina, Functional Properties of Hemocoagulation In Calves Of Dairy Nutrition, Res. J. of Pharmaceut., Biolog. and Chemical Sci., 9(5), 1016-1022 (2018)
36. S.Yu. Zavalishina, Deficiency Of Iron As A Cause Of Dysfunction In Calves And Piglets, Res. J. of Pharmaceut., Biolog. and Chemical Sci., 9(5), 978-983 (2018) 